\title{
'Tutoring Is Not Proofreading'. Exploring the Perceptions of Writing Tutors at University Writing Centres, Saudi Arabia: An Exploratory Study
}

\author{
Rehab Alowayid ${ }^{1}$ \\ ${ }^{1}$ School of Modern Languages \& Lingustics, Southampton University, Southampton, United Kingdom \\ Correspondence: Rehab Alowayid, School of Modern Languages \& Lingustics, Southampton University, \\ Southampton, United Kingdom.
}

Received: October 6, 2020

doi: $10.5539 /$ elt.v13n12p5

\begin{abstract}
Academic discourse is highly complex and requires writers to follow specific writing conventions. Many Saudi university students have underdeveloped writing skills (Al-Khairy, 2013). One way to assist second language (L2) learners and develop their academic writing skills is through academic language support offered by writing centres. The challenge for writing centre tutors lies in the predominant belief among many L2 students that tutors' only role is to fix students' mistakes. Although there has been significant growth in writing centres in Saudi universities, the perceptions of writing tutors concerning tutoring non-native students are still under-researched. This study uses thematic analysis to explore the role of writing tutorials as perceived by writing centre tutors in Saudi settings. Data were obtained using an interpretive inquiry through individual interviews of two tutors. The main findings of the interviews were that tutors perceived proofreading requests, low writing proficiency of tutees and tutees' understanding of tutors' role as influencing their tutorial practices. The implementation of this study may help regulate the role of tutors in writing centres in Saudi universities by highlighting new avenues that can improve writing tutorials, especially in Saudi Arabia.
\end{abstract}

Keywords: writing centre, writing support, proofreading trap, writing tutorial, tutors

\section{Introducing the Problem}

Writing centres have only been introduced within the Saudi higher education system between 2011 and 2014 . Hence, there is minimal research into this area (Eusafzai, 2018). Few studies have been conducted to examine writing centre tutorials in the Saudi English as a foreign language (EFL) context (e.g., Dalha, 2017; Eusafzai, 2018). The results of interviews conducted in these studies with stakeholders, including tutors and directors of writing centres in Saudi Arabia, revealed a lack of understanding of the writing centres' functions among tutors and tutees. However, these studies were preliminary in nature, and tutors' perceptions of their role and the challenges they face in writing centres were left unexplained. The purpose of this study is to explore the perceptions of university writing centre tutors in Saudi Arabia to understand the nature of tutors' role in writing tutorials and the challenges they face while tutoring non-native English students (NNESs).

\subsection{Exploring the Importance of the Problem}

Many L2 writers experience difficulties in writing and need personalised help that exceeds the limits of classroom instruction (Kim, 2018). Writing centres, for instance, provide personalised assistance that can remedy writing difficulties. Unlike classroom writing instructors, tutors in writing centres do not merely mark and correct students' errors; instead, they facilitate learning and guide tutees to become better writers (Harris \& Silva, 1993). Put differently, tutors' support and guidance in writing spaces can meaningfully contribute to tutees' academic development and growth, especially in higher education (Govender \& Alcock, 2020). Indeed, writing centre tutors offer opportunities and personalised scaffolding for tutees who express writing insecurities (Mackiewicz \& Thompson, 2014). This underscores the need to explore the role of tutors and their tutoring practices to enhance the efficacy of writing centre work. Because writing centres have only been recently introduced within the Saudi higher education system, more research into this area is needed (Eusafzai, 2018). In response to this scarcity, the current study was conducted to reflect on how writing centre tutors understand their role in tutoring L2 writers. 


\section{Review of Literature}

Writing centres first emerged in the US in the 1960s (North, 1984). Different names were used in the literature, including 'writing lab', 'skill centre' and 'writing clinic' (Carino, 1995; Harris, 1995; Moore, 1950). Carino (1995) posited that writing centres were first introduced as part of a classroom approach to writing instruction aimed primarily at helping struggling students. Later, these writing labs were introduced in higher education systems as independent from classroom instruction to help students overcome their fears and improve their writing proficiency. With the evolution of free-standing writing centres, they began to offer tutoring support to all students regardless of their writing abilities (Carino, 1995).

North (1984) criticised the misconceptions that many stakeholders held about the role and function of writing centres. Similarly, Leahy (1990) highlighted the lack of awareness amongst teachers and students regarding the role of a writing centre. North explained that faculty members, students and administrators typically viewed writing centres as a 'fix-it shop' whereby the tutor fixes students' grammatical errors. In reality, their actual purpose is to help students become better writers. As a result, a non-proofreading policy has been introduced in many writing centres across the US and Canada to maintain the writing centres' core practice of assisting students. The policy was established due to a shift in instructional pedagogy from a product-focused one to a writing-process approach (Kim, 2018). Such policies have been widely adopted to regulate the type of help administered while prioritising content, including arguments over surface features such as grammar (Winder et al., 2016). However, these policies have been studied within native English educational contexts, while few studies have explored L2 English contexts.

In investigating tutorials with NNESs, researchers have noted that tutoring NNESs in writing centres can be challenging and called for understanding the work of writing centre tutorials to help students improve their writing skills (Kim, 2018; Thonus, 1993). In a similar vein, Ronesi (2009) indicated that although the number of writing centres outside the US has increased, tutors' work in international writing centres remains controversial. One possible reason for this according to Ronesi is that tutors' practices vary to meet the unique linguistic and cultural needs of local individuals. However, little research has been conducted to date that studies writing centres in non-native English contexts (Bakkar, 2019; Kim, 2018; Lee, 2014; McHarg, 2013; Ronesi, 2009). Therefore, this research was conducted to addresses the ongoing controversy between the current ESL pedagogical practices and the core theoretical foundations of writing centres. To discuss how tutors in ESL/EFL writing centres perceive their role, a summary of relevant literature that supports this study's assertions is discussed below.

\subsection{Non-Native English and Writing Centres}

Thonus (1999) compared the discourse used in tutorial interaction with native English students (NESs) and writing tutorials with NNESs (mainly Asian students) and concluded with a call for further research, especially in writing venues for second- and foreign-language writers. The study utilised discourse analysis of 12 tutorial transcripts and interviews with six NESs and six NNESs studying at Indiana University. The analysis of the tutorial discourse demonstrated that tutors spoke less with their NNESs than they did with their NESs. This finding is important because it may imply differences in tutoring NNESs, suggesting the importance of understanding tutors' beliefs and practices. Moreover, the discourse analysis of the tutorial language revealed that tutorials with NNESs were characterised by more directives and less conversational involvement. These findings are in line with Williams (2004), who found that when working with NNESs, tutors tend to dominate the interaction through the use of directives, including imperatives and modals. Such consistency across studies suggests differences in writing tutorials with NNESs and the challenges faced by tutors in tutoring this type of student. Nonetheless, such studies set out to compare tutoring NNESs with NESs within native English environments. Today, 'the major population who visits the writing center is second language learners' (Kim, 2018, p. 23). Given this reality, studies that closely examine data collected from writing centres outside native English contexts are useful 'to improve and refine [the work of writing centre] on a continuing basis' (Stock, 1997, p. 17). This study addresses the scant research on writing centres particularly in the Saudi context and aims to contribute to this under-researched area of inquiry. Specifically, it focuses on exploring the perceptions of two tutors working in writing centres in Saudi Arabia in terms of their experiences and the challenges that they have faced working with EFL writers.

Researchers have noted some challenges in tutoring NNESs because many writing centres espouse North's (1984) philosophy that the primary goal of writing centres is to produce better writers, not better texts (Kim, 2018; Williams, 2004). This policy has led many writing centres specifically in native English environments to stress that the role of a tutor is not to proofread tutees' papers but instead to help student writers learn how to improve their writing in a non-directive manner that addresses students' concerns (Kim 2018; Okuda \& Anderson, 2018). The claim that tutors in international writing centres outside the US, especially in the Middle East, struggle in their 
instructional pedagogy prompted the current study's objective of examining how writing tutors in Saudi Arabia perceive their role (Kim, 2018; Lee, 2014; Ronesi, 2009). Understanding tutors' role in international writing centres has the potential to help elucidate how tutors behave in tutoring non-native English writers to develop efficient writing tutorials that suit their needs.

In relation to this, Aldohon (2020) stressed that understanding tutors' espoused ideas and perceptions can help in understanding tutors' behaviours and the tutoring approaches they utilise. Thus, understanding the role of writing tutors has the potential to resolve the confusion about the function of writing centres.

Govender and Alcock (2020) maintained that reflecting on tutors' role in the writing centre is critical because tutors are facilitators of learning and criticality. Kim (2018) debated the controversy over the role of tutors in writing centres and called for the examination of the pedagogy of writing tutorials. In examining tutorials with NNESs, Kim (2018) reported that most ESL and EFL students who visit writing centres seek proofreading help. Therefore, Kim argued that collaborative negotiation in writing tutorials is pivotal not only for tutoring but also for familiarising L2 writers with the writing centre pedagogy. Ostensibly, Kim's recognition of the role of collaboration in writing tutorials supports the need for understanding the type of writing and language support provided in writing centres as viewed by writing tutors. Writing centre studies conducted in Arabic contexts have also described the mismatch between students' expectations of writing tutorials and the current practices of writing centres (Al Murshidi \& Al Abd, 2014; Bakkar, 2019; McHarg, 2013). This divergence may deter students from utilising the support services effectively.

Relatedly, Al Murshidi and Abd (2014) utilised a mixed-methods approach to survey the perceptions of tutees and a writing centre director in the United Arab Emirates (UAE). They found that $76 \%$ of the 50 student participants who visited the writing centre at UAE University were unaware of how to use the centre effectively. The study stands out because it involved EFL Emirati students who share similar cultural and linguistic characteristics with Saudi students. Al Murshidi and Abd further highlighted that students perceived the writing centre as a place in which they could edit their assignments. The interview with the writing centre supervisor revealed a contradiction between the type of support the centre provided and the students' beliefs.

Eusafzai (2018) stressed the importance of writing centres in improving the academic writing skills of Saudi undergraduate students. Through interviews with writing centre directors and tutors, the study revealed some features of Saudi writing centres, including the non-directive tutoring approach to developing students' literacy skills. However, the tutor interviews demonstrated inconsistencies and ambiguities in the tutoring practices offered by the writing centres, underscoring the need for understanding tutors' beliefs and their perceived ideals. Likewise, Dalha (2017) investigated the manifestation of critical thinking strategies in tutoring male students in the writing centre at the Royal Commission Yanbu Colleges and Institutes, Saudi Arabia. In the qualitative study, nine tutors were observed over 14 weeks, and semi-structured interviews were conducted to ascertain both tutors' and tutees' understanding of critical thinking strategies in academic writing. The results indicated an absence of critical thinking strategies in the observed tutoring sessions, while the interview data showed the dominance of a directive tutoring approach. These results highlighted an area for future research, given that much uncertainty still exists about how tutors perceive their role in writing tutorials. These are valuable results for the present study to explore. Notably, there is a gap between ESL program practices that emphasise surface features (including grammar, syntax and accuracy) and those of writing centres (Moussu, 2013). Therefore, the present study aims to investigate tutors' perceptions about their practices when tutoring NNESs. To the best of the researcher's knowledge, of the above-reviewed studies only two have discussed writing centre tutorials in the Saudi context: Eusafzai (2018) and Dalha (2017). The results of interviews with stakeholders in these studies revealed that tutors have a vague understanding of their role. Utilising a qualitative interpretive mode of inquiry, the present study seeks to answer the following questions:

Research question 1: How do writing tutors perceive the nature of writing tutorials in university writing centres in Saudi Arabia?

Research question 2: What are the challenges of writing tutorials as perceived by writing tutors?

Research question 3: What are the expectations of writing centre tutors regarding how their tutoring role is perceived?

\section{Methodology}

This study utilised a qualitative interpretive inquiry to elicit writing centre tutors' views on their role when working with NNESs. Gubrium and Holstein (1997) conceived of qualitative interpretive inquiry as an approach that provides naturalistic descriptions of participants' orientations. Through semi-instructed interviews, this study 
explored writing tutors' expressed perceptions about dealing with proofreading requests in the centres, the type of writing support they could prove and their role when tutoring English non-native writers. Importantly, qualitative methods were used to allow for an in-depth exploration of participants' perceptions and beliefs (Heigham \& Croker, 2009; Merriam \& Tisdell, 2015; Pearson et al., 2015).

\subsection{Participants and Setting}

There are four main writing centres in Saudi higher education: two of these centres are in the capital city of Riyadh, and the other two are situated on the western coast of the country, specifically in Jeddah and Yanbu (Eusafzai, 2018). These centres are summarised in the following table:

Table 1. List of Writing Centres in Saudi Higher Education

Name of the writing centre

1 The Writing Studio at Princess Nourah bint Abdulrahman University (WSPNU)

2 The Centre for Writing in English at King Saud University (CWEKSU)

3 The Academic Writing Centre at King Abdulaziz University in Jeddah (AWCKAU)

4 The Writing Center for the Royal Commission for Yanbu Colleges and Institutes at Yanbu Alsinaayah (RCYCI)

Two female writing tutors from two university writing centres in Saudi were interviewed to identify their perceptions regarding their role while tutoring NNESs. Due to difficulties in reaching the participants for face-to-face interviews, online interviews were conducted and lasted between 25 to 35 minutes for each participant. These two participants were recruited based on their current roles as tutors providing writing consultations with different tutoring experiences and who were willing to voluntarily participate in this study. For the sake of research ethics, informed participant consent was electronically obtained via participants' official institutional accounts before the commencement of the interviews. The participating tutors were informed about the purpose of the study and the nature of the investigation. Care was taken to answer participants' questions relevant to their participation while emphasising their right to leave the study at any time. Efforts were made to record the exact language and phrases used by each participant. In addition, pseudonyms for participants and centres were used to ensure the anonymity and confidentiality of the provided information. According to Pearson et al. (2015), ensuring the confidentiality and anonymity of individuals and research locations can mitigate ethical challenges associated with undertaking a qualitative enquiry.

\subsection{Semi-Structured Interviews}

Flick (1998) explained that semi-structured interviews invite respondents to naturally express what is on their minds. Research has posited that within a writing centre context, semi-structured interviews may offer adequate descriptions of the investigated phenomenon (Thonus, 1999). For the collection of data in this paper, semi-structured interviews were utilised (See Appendix A). Presumably, semi-structured interviews allow for eliciting responses in a less controlled form, enabling deeper probing questions (Dörnyei, 2007). Aldohon (2020) noted that discussions with writing tutors enable the understanding of any convergence or divergence in tutors' perceptions. The interview questions were qualitative in nature and were created to explore participants' perceptions and expectations (See Appendix A). Most of the topics covered in the interview questions were derived from recurrent themes in studies that investigated writing tutorials for non-native English learners, specifically studies conducted by Kim (2018) and Ronesi (2009). Except for questions related to tutors' expectations, it is a topic that is primarily explored within this study to uncover perspectives grounded in participants' lived experiences. Thus, in the interviews, the writing tutors were asked 12 main questions concerning the nature of the writing centre, tutors' roles in tutorial sessions, what difficulties they have faced and what suggestions they might have for improving their tutoring practices and approaches. The obtained answers were transcribed using the Vienna-Oxford International Corpus of English (VOICE) conventions (See Appendix B).

\subsection{Procedure}

A pilot interview was conducted with a peer tutor by the end of July 2020 to ensure the clarity of the interview questions. Modifications were then made to two questions by rephrasing them based on the received feedback. In addition, at the pilot phase, the number of questions was 15 , which was later reduced to 12 . Thus, 12 questions were developed to collect data from the two participating tutors, eliciting their perceptions. These 12 questions, 
however, did not strictly limit the focus of the interview. For the analysis of the obtained data, data were initially categorised using the topics of the interview research questions to organise the coding of data. Additional organisational codes that emanated from participants' responses (e.g. 'level of proficiency') were used. The obtained data were analysed using an inductive analytic approach by identifying common themes from the tutors' answers. The inductive analytic approach allows for the categorisation of emanating themes from the data to capture meaningful and contextualised accounts of human experiences and perceptions within the phenomenon under study (Thorne et al., 2004).

\section{Results and Discussion}

To answer the study questions, themes of individual data were first identified independently. Then identified themes were compared between participants and categorised into perceptions and expectations. The results, data analysis and discussion are presented according to the iterative and salient themes drawn from the interviewees' responses. The themes that emerged were identified based on the researcher's reflection on the research's primary focus and questions. The development of this thematic framework guided the data analysis and helped to penetrate deeper into the participants' perceptions. With a close look at the data, only parts of the tutors' responses that are closely linked with the research questions are presented to highlight and explain commonalities and dichotomies in tutors' beliefs and expectations. For ease of discussion, the identified themes are discussed below.

\subsection{Tutors' Beliefs about the Proofreading Trap}

To answer the first research question regarding the nature of writing tutorials in university writing centres, the two participants demonstrated a mismatch between the tutor's actual role in the centre and proofreading requests. Related to this theme, Kim (2018) reported that tutors in writing centres encounter proofreading requests all the time, specifically by L2 writers and tutees who visit writing centres for the first time. When dealing with proofreading requests, Kim suggested that it becomes vital for tutors to adapt their instruction to familiarise tutees with the role of tutors in writing tutorials. One way to raise tutees' awareness, according to Kim, is through collaborative negotiations to achieve mutual understanding about 'what' and 'how' tutors work with writing centre tutees. Collaborative and joint discussions could promote mutual understanding because proofreading practices in writing centres are deemed inappropriate (Chromik, 2002). It is therefore not surprising that the proofreading trap was found repeatedly in the interview data of the two tutors. When interviewees were asked to describe their perceived role, both tutors commented on experiencing proofreading requests due to tutees being unaware of the tutors' role. Tutor A assumed that

as a tutor working particularly with English non-native students, my role is really not very definite. I consider myself as a facilitator who is (.) trying all the time to close sort of the knowledge gap (2) helping students to understand that I am in the centre to improve their writing and not to rewrite their papers or correct every mistake. But eeh, [. . .] I don't know if I can also add proofreading to the list of my role@. Still, it happens anyway so....(@@@) Very many students think it is OUR role as tutors to proofread their work and fix their grammatical mistakes as well on top of editing their papers.

This belief was also clearly evident in Tutor's B words when she explained her role:

The moment I engage with a student on the first dialogue, I get to know whether the student sees me as a tutor or someone else. I mean you know the student's level of proficiency as EFL [...] (thinking deeply, then conversing slowly) determines my role in the tutorials (2) tutoring is fun, but when the first thing that brings students to the centre is proofreading then this makes my role a bit challenging I meant they are English non-natives so need more help that seems unpleasantly necessary.

It is worth noting that while Tutor A mentioned the proofreading request trap explicitly, Tutor B mentioned that proofreading is challenging, and it seemed unavoidable to accommodate students' varying proficiency levels. In sum, the data revealed that the two tutors had a shared perspective of the proofreading trap, highlighting the importance of mutual understanding through tutor-tutee negotiations. It can be inferred that the proofreading trap may affect the role of tutors in writing centres, especially when tutoring NNESs as opposed to NESs. Nordlof (2014) asserted that adopting a scaffolding model in writing centre tutorials that encompasses collaborative learning can help tutors adjust their tutoring approaches to students' different levels of learning. Similarly, Hawkins (1984) noted that tutor-tutee collaboration promotes greater involvement. This finding could possibly inform current writing tutors to reflect on and assess their tutoring practices because the tutors' role is integral to the efficacy of writing centres. Further research that explores the role of tutor-tutee collaboration is recommended to provide insights concerning effective writing tutorial approaches. 


\subsection{Tutors' Beliefs about the Type of WritingConsultation and Tutorial Challenges}

The results in this section answer the second research question by discussing some challenges of writing tutorials as expressed by the participants. Although a lack of a uniform pedagogy for tutoring non-native English tutees in writing centres in the Saudi context has been realised in the extant literature (e.g. Dalha, 2017), it was important to identify how tutors perceive their role in terms of the tutoring support they can provide and the challenges they face. Doing so can enhance the understanding of the available support in writing centres to resolve challenges and ambiguities that can occur during tutorials with EFL tutees. In answering the question about the role they fulfil in relation to the type of support they offer and the challenges they encounter, the tutors stressed the importance of addressing the various learning needs for successful tutorials. As Tutor A noted,

My role in the centre is not simple that means I am (2) a tutor and a kind of coach hh (.) and sometimes a reviewer as well [. . .] customising my support to best serve the needs of the students. Generally speaking, I help students with correct spelling and grammatical structures. Working on IMPROVING their papers specifically helping them to improve critical arguments to meet the demands of academic writing.

Clearly, Tutor A believed that her decisions about the type of tutoring support stem mainly from students' different writing needs. This finding reinforces previous research's findings that in writing, learners of English struggle more than native writers, thereby requiring personalised assistance to address their writing concerns (Dalha, 2017; Govender \& Alcock, 2020; Harris \& Silva, 1993; Kim, 2018). This implies that tutees' writing needs influence the work of tutors, affecting their pedagogical approaches and the type of support they provide. When describing the type of assistance provided in writing centre conferences, Tutor B seemed to endorse a diagnostic approach that focused on individuals' needs to aid university L2 students in developing their writing and overcoming language-related challenges. That is, the provided support is primarily directed to each student's needs. Likewise, the interview data revealed that Tutor B viewed her support being primarily responsive in nature as she explained her role:

As far as I'm concerned (2) honestly whatever support a writing student may need, I can do. They depend on us for direction, (@@ I think being there for students without setting ermm sort of limits for them hh (.) can't only improve their literacy skills but also help to reduce their anxieties about writing in a foreign language.

Tutor B referred to not only support with language issues but also assistance with the added anxieties tied to EFL levels of English proficiency. In summary, the tutors held a strong belief about their supportive role. While Tutor A exhibited a more remedial view, Tutor B envisioned a more supportive and affective view. Taken together, both tutors perceived writing centres as hubs through which individuals discuss their concerns and challenges with respect to academic writing. This assessment supports the significance of listening and responding strategies while providing writing support (Lawson, 2015). The finding also suggests that it is necessary for writing tutors to apply a range of tutoring approaches to serve the unique needs of each individual using the support of writing centres.

\subsection{Tutors' Expectations about their Roles in the Centre}

This section presents the results regarding tutors' expectations about how their role is perceived. Tutor A highlighted that students must be aware of the role of the writing centre before visiting it. This involves helping students understand the role of the tutor and the types of support available for them in writing centres:

If $<@>$ students can be given guidelines and a clear definition of the role of tutors $<@>$ when they are still new to the institution, (4) to make sure that everyone benefit from the centre tremendously, (2) learners have to realise to what extent they can receive support from US because if they do not understand THIS, we would not be able to help them appropriately. A tutor is not a teacher per se, I do not provide course content but I help students to think and rethink.

Kim (2018) has also confirmed that understanding the role of tutors in writing centres allows tutors and tutees to work mutually with each other, enabling joint discussions and involvement. By probing Tutor A, it was found that her tutoring role in the centre was affected by tutees' beliefs and perspectives about the work and function of writing centres. That is, tutees' expectations and familiarity with the writing centre philosophy shaped her tutoring approaches and practices. Furthermore, when Tutor A was asked whether there was anything else she would like to add, the tutor stressed the importance of collaboration with course instructors because students bring to the centre their traditional beliefs that their teachers are the primary source of knowledge, and the role of writing tutors is to align with academic instructors' predefined pedagogical goals. 
This suggests that students' belief that teachers are the primary figures of authority may obstruct tutors' roles in writing centres. The interview data showed that Tutor A considered course instructors' beliefs about the writing centre to determine the way she practised in writing tutorials. This finding was in line with Leyland (2020), who argued that collaboration between writing centre tutors and academic instructors plays a vital role in determining the effectiveness of writing tutorials. However, it was unclear from the interview with Tutor B whether she believed that the preferences of academic instructors could possibly affect her practices as a writing tutor. Nevertheless, Tutor B reported that with EFL students in mind, writing centres provide students with further opportunities to develop their writing skills and overcome the challenges of writing in a foreign language:

Yeah, (. . ) I believe that nobody should be discouraged from visiting the centre hh (.) because writing centres acknowledge the needs of English language learners and hh (.) are there basically $<@>$ to help them develop their skills $<@>$ instead of hindering their learning.

This finding suggests that writing centres vary in their tutoring practices because they appear to be context dependent (Moussu, 2013). The local context seems to shape tutors' practices in the writing centre. One way to understand this is perhaps to study tutors' role as socially situated by utilising a socio-constructivist framework. The assertion made by Tutor B that 'students who come to this centre(.) bring with them the idea that the centre is another place of teacher-student classroom interaction' suggests that future studies may go far by investigating structures of interaction within a writing centre context. Interestingly, the discrepancy in how each tutor speculated on her role within the writing centre may underscore Lerner's emphasis on the importance of 'role knowledge' for the success of writing tutorials $(2019$, p. 115). Finally, the growth of writing centres that operate outside native English contexts and the limitations of this study suggest that more research on international writing centres is needed to conceptualise and advance research on EFL/ESL writing centres.

\section{Conclusion}

This study demonstrates that understanding tutors' role is integral to the success of writing centres. By and large, understanding how tutors perceive their role could inform and enhance the work of writing centres. The reflective nature of the analysis makes it possible to explore overlapping and divergent views. Considering the increasing number of writing centres in Saudi Arabia and the dearth of research pertaining to writing centres, it appears crucial to explore the many roles that tutors fulfil when tutoring EFL tutees. Several themes emerged following the analysis of the interview data. Overall, the participating tutors perceived their role as helping tutees improve their writing and ultimately become independent writers instead of proofreading tutees' papers. They also believed that a clear understanding about their role in the centre could demystify such misunderstandings to improve the type of support that tutors can render when tutoring NNESs. Equally, the interviewed tutors voiced their concerns about how their role is placed in a second-class status. For example, the participating tutors reflected on how advisees may perceive tutors' role as secondary and therefore may not communicate effectively with tutors. This concern reinforces the need for institutional changes to bring increased attention to tutors' roles and needs as integral components of writing centre success.

In the Saudi context, in which the number of writing centres is rapidly growing, understanding the role of tutors as perceived by tutors will provide the opportunity to regulate the work and practice of tutors when tutoring EFL students. Exploring the tutors' perceptions may, therefore, help to raise awareness about writing centre tutors in an effort to allay the difficulties they may face when working with non-native English tutees. In turn, the gap between tutors' perceptions and actual practices in the writing centre can be bridged. This small study has a restricted scope that may not fully reflect the perceptions and beliefs of writing centre tutors in Saudi Arabia. Although this study gives a limited glimpse into the perceptions of two writing tutors in two Saudi university writing centres, it suggests that understanding tutors' perceptions about their role can potentially help balance tutors' practices in writing tutorials with NNESs. Determining whether tutors' beliefs are also shared by other tutors deserves further consideration. Given this, additional research should be conducted utilising focus group interviews to examine whether tutors change their expectations and beliefs. It is thus recommended that writing centre tutors build a tutoring network to reflect on their beliefs, experiences, practices and areas for professional development. Future studies are recommended to examine how tutees perceive the role of tutors in writing centres and discuss the discrepancies, if any, between tutors' beliefs and those of tutees.

\section{Acknowledgments}

This exploratory paper is an adaptation of my $\mathrm{PhD}$ research interest; therefore, I received no funding for conducting and publishing this article. 


\section{References}

Al Murshidi, G., \& Al Abd, K. (2014). UAE university students' awareness of using the writing center. Higher Education Studies, 4(3), 58-63. https://doi.org/10.5539/hes.v4n3p58

Aldohon, H. (2020). Writing centre conferences: Tutors' perceptions and practices. Educational Studies, 1-20. https://doi.org/10.1080/03055698.2020.1717931

Al-Khairy, M. A. (2013). Saudi English major undergraduates' academic writing problems: A Taif University perspective. English Language Teaching, 6(6), 1-12. https://doi.org/10.5539/elt.v6n6p1

Bakkar, B. B. (2019). The writing center's role in the academic life of an English foreign language student from an instructor's perspective. Arab World English Journal, 10(3), 32-42. https://doi.org/10.24093/awej/vol10no3.3

Carino, P. (1995). Early writing centers: Toward a history. The Writing Center Journal, 15(2), 103-115. Retrieved from https://www.jstor.org/stable/43441973

Chromik, M. (2002). Proofreading, its value, and its place in the writing center (ED476401). ERIC. Retrieved from https://eric.ed.gov/?id=ED476401

Dalha, L. (2017). Developing students' critical thinking skills in writing at a Saudi Arabian writing centre. Writing Centers in the Higher Education Landscape of the Arabian Gulf, 109-128. https://doi.org/10.1007/978-3-319-55366-5 7

Dörnyei, Z. (2007). Research methods in applied linguistics: Quantitative, qualitative, and mixed methodologies. Oxford University Press.

Eusafzai, H. A. K. (2018). The emergence of writing centres in the Saudi higher education landscape: A genealogical investigation. Writing Centers in the Higher Education Landscape of the Arabian Gulf, 3-20. https://doi.org/10.1007/978-3-319-55366-5_1

Flick, U. (1998). An introduction to qualitative research. Sage Publications.

Govender, N., \& Alcock, A. (2020). Humanising writing centre practice: Peer tutor reflections at a university of technology. Africa Education Review, 17(1), 18-34. https://doi.org/10.1080/18146627.2018.1467735

Gubrium, J. F., \& Holstein, J. A. (1997). The new language of qualitative method. Oxford University Press.

Harris, M. (1995). Talking in the middle: Why writers need writing tutors. College English, 57(1), 27-42. https://doi.org/10.2307/378348

Harris, M., \& Silva, T. (1993). Tutoring ESL students: Issues and options. College Composition and Communication, 44(4), 525-537. https://doi.org/10.2307/358388

Hawkins, T. (1984). Writing centers: Theory and administration (pp. xi-xiv). NCTE.

Heigham, J., \& Croker, R. (2009). Qualitative research in applied linguistics: A practical introduction. Springer. https://doi.org/10.1057/9780230239517

Kim, J. (2018). Could you check my grammar? The forbidden request in the university writing center. International Journal of Research, 7(4), 21-37. https://doi.org/10.5861/ijrsll.2017.2000

Lawson, D. (2015). Metaphors and ambivalence: Affective dimensions in writing center studies. WLN: A Journal of Writing Center Scholarship, 40(3-4), 20-27.

Leahy, R. (1990). What the college writing center is-and isn't. College Teaching, 38(2), 43-48. https://doi.org/10.1080/87567555.1990.10532187

Lee, A. S. (2014). A transcultural framework proposal for international writing centers. In E. Doman (Eds.), Insight into EFL teaching and issues in Asia (pp. 129-145). Cambridge Scholars Publishing.

Lerner, N. (2019). Reformers, teachers, writers: Curricular and pedagogical inquiries. Utah State University Press. https://doi.org/10.7330/9781607328810

Leyland, C. (2020). Academic writing tutorials for international students: Deferring to an expert and follow-up advice. Language and Education, 34(3), 212-230. https://doi.org/10.1080/09500782.2019.1682008

Mackiewicz, J., \& Thompson, I. (2014). Instruction, cognitive scaffolding, and motivational scaffolding in writing centre tutoring. Composition Studies, 42(1), 54-78.

McHarg, M. (2013). A sociocultural exploration of English faculty perceptions of the writing center in the Qatari 
context. Arab World English Journal, 4(4), 17-28.

Merriam, S. B., \& Tisdell, E. J. (2015). Qualitative research: A guide to design and implementation. John Wiley $\&$ Sons.

Moore, R. H. (1950). The writing clinic and the writing laboratory. College English, 11(7), 388-393. https://doi.org/10.2307/586024

Moussu, L. (2013). Let's talk! ESL students' needs and writing centre philosophy. TESL Canada Journal, 30(2), 55-68. https://doi.org/10.18806/tesl.v30i2.1142

Nordlof, J. (2014). Vygotsky, scaffolding, and the role of theory in writing center work. The Writing Center Journal, 34(1), 45-64.

North, S. M. (1984). The idea of a writing center. College English, 46(5), 433-446. https://doi.org/10.2307/377047

Okuda, T., \& Anderson, T. (2018). Second language graduate students' experiences at the writing center: A language socialization perspective. TESOL Quarterly, 52(2), 391-413. https://doi.org/10.1002/tesq.406

Pearson, M. L., Albon, S. P., \& Hubball, H. (2015). Case study methodology: Flexibility, rigour, and ethical considerations for the scholarship of teaching and learning. The Canadian Journal for the Scholarship of Teaching and Learning, 6(3), 12. https://doi.org/10.5206/cjsotl-rcacea.2015.3.12

Ronesi, L. (2009). Theory in/to practice: Multilingual tutors supporting multilingual peers: A peer-tutor training course in the Arabian Gulf. The Writing Center Journal, 29(2), 75-94. Retrieved from https://www.jstor.org/stable/43460758?seq=1

Stock, P. L. (1997). Reforming education in the land-grant university: Contributions from a writing center. The Writing Center Journal, 18(1), 7-29. Retrieved from https://www.jstor.org/stable/43442034?seq=1

Thonus, T. (1993). Tutors as teachers: Assisting ESL/EFL students in the writing center. The Writing Center Journal, 13(2), 13-26. Retrieved from https://www.jstor.org/stable/43441927?seq=1

Thonus, T. (1999). NS-NNS interaction in academic writing tutorials: Discourse analysis and its interpretations (ED432916). ERIC. Retrieved from https://eric.ed.gov/?id=ED432916

Thorne, S., Kirkham, S. R., \& O’Flynn-Magee, K. (2004). The analytic challenge in interpretive description. International Journal of Qualitative Methods, 3(1), 1-11. https://doi.org/10.1177/160940690400300101

Williams, J. (2004). Tutoring and revision: Second language writers in the writing center. Journal of Second Language Writing, 13(3), 173-201. https://doi.org/10.1016/j.jslw.2004.04.009

Winder, R., Kathpalia, S. S., \& Koo, S. L. (2016). Writing centre tutoring sessions: Addressing students' concerns. Educational Studies, 42(4), 323-339. https://doi.org/10.1080/03055698.2016.1193476 


\section{Appendix A}

Tutor Semi-Structured Interview Schedule

Tutoring Background

Proofreading Trap

Writing Centre and Support

Perceptions of EFL and Tutorial Pedagogy

Tutor's Concerns

Concluding Question
Prompts: How would you define your role in the centre? How do you feel when a student asks you to proofread her paper? How long have you been working as a writing tutor?

Prompts: How do you describe the differences between tutors and proofreaders, if any? How do you deal with proofreading requests?

Prompts: What consultation support can you provide? Describe your perception of the work of the writing centre. Describe your perception of your role as a tutor. How do you decide what sort of tutoring approach to utilise?

How has the tutee's proficiency level affected your tutoring pedagogy?

What are your main concerns about tutoring non-native English speakers (NNES)?

What challenges have you had with tutoring NNESs? What barriers, if any, can you identify as a tutor in the writing centre? What changes do you think could be made to better improve tutorials in the writing centre?

Is there anything else you would like to add?

\section{Appendix B}

\section{Key to Transcription Conventions}

Transcription conventions for the interview (adopted from the Vienna-Oxford International Corpus of English [VOICE] version 2.0 online)

$\begin{array}{ll}\text { Key } & \text { Conventions } \\ \text { TA } & \text { Tutor A } \\ \text { TB } & \text { Tutor B } \\ \text { UTTERANCE } & \text { Capitalised to show emphasis } \\ <@>\text { utterance }<>> & \text { Speaking with laughter } \\ (.) & \text { Short pause } \\ {[\ldots]} & \text { Speaker's gap } \\ (2) & \text { Short pause for } 2 \text { seconds } \\ \text { @ } & \text { Laughter } \\ \text { Hh }(.) & \text { Relatively short pause for breathing } \\ (4) & \text { A pause for } 4 \text { seconds } \\ \text { I I } & \text { Repetition }\end{array}$

\section{Copyrights}

Copyright for this article is retained by the author(s), with first publication rights granted to the journal.

This is an open-access article distributed under the terms and conditions of the Creative Commons Attribution license (http://creativecommons.org/licenses/by/4.0/). 